\title{
Evaluación clínico-radiológica y clasificación de la bronquiolitis del adulto
}

FERNANDO SALDÍAS P. ${ }^{1}$, ORLANDO DÍAZ P. ${ }^{1}$, SERGIO GONZÁLEZ B. ${ }^{2}$, RODRIGO OSSES A. ${ }^{3}$

'Departamento

de Enfermedades

Respiratorias.

${ }^{2}$ Departamento de

Anatomía Patológica.

Facultad de Medicina,

Pontificia Universidad

Católica de Chile, Santiago,

Chile.

${ }^{3}$ Servicio de Medicina,

Hospital de Los Ángeles,

VIII Región.

Recibido el 20 de enero de

2011, aceptado el 24 de mayo de 2011.

Correspondencia a: Dr. Fernando

Saldías Peñafiel

Departamento de

Enfermedades Respiratorias

Pontificia Universidad

Católica de Chile.

Teléfonos: (562) 6331541

(562) 3543242

Fax: (562) 6335255

Marcoleta 350, Santiago,

Chile.

E-mail: fsaldias@med. puc.cl

\section{Bronchiolar disorders: clinical-radiological assessment and classification}

Bronchiolar disorders are generally difficult to diagnose. A detailed clinical history may point toward a specific diagnosis. Pertinent clinical questions include history of smoking, collagen vascular disease, inhalation injury, medication use and organ transplantation. It is important also to evaluate possible systemic and pulmonary signs of infection, evidence of air trapping, and high-pitched expiratory wheezing, which may suggest small airways involvement. Pulmonary function tests and plain chest radiography may demonstrate abnormalities; however, they rarely prove sufficiently specific to obviate bronchoscopic or surgical biopsy. High-resolution CT (HRCT) scanning of the chest is often an important diagnostic tool to guide diagnosis in these difficult cases, because different subtypes of bronchiolar disorders may present with characteristic image findings. Some histopathologic patterns of bronchiolar disease may be relatively unique to a specific clinical context but others are nonspecific with respect to either etiology or pathogenesis. Primary bronchiolar disorders include acute bronchiolitis, respiratory bronchiolitis, follicular bronchiolitis, mineral dust airway disease, constrictive bronchiolitis, diffuse panbronchiolitis, and other rare variants. Prominent bronchiolar involvement may be seen in several interstitial lung diseases, including hypersensitivity pneumonitis, collagen vascular disease, respiratory bronchiolitis-associated interstitial lung disease, cryptogenic organizing pneumonia, and pulmonary Langerhans' cell histiocytosis. Large airway diseases that commonly involve bronchioles include bronchiectasis, asthma, and chronic obstructive pulmonary disease. The clinical and prognostic significance of a bronchiolar lesion is best determined by identifying the etiology, underlying histopathologic pattern and assessing the correlative clinic-physiologic-radiologic context.

(Rev Med Chile 2011; 139: 1218-1228).

Key words: Bronchiolitis; Diagnosis, differential; Lung diseases, obstructive.
L a enfermedad bronquiolar o bronquiolitis corresponde a un proceso inespecífico, inflamatorio o fibrótico, de múltiples orígenes que involucra a los bronquiolos y alvéolos, se manifiesta por síntomas respiratorios inespecíficos y compromiso funcional variable, que difieren en su evolución, gravedad y pronóstico ${ }^{1-3}$. Desde el punto de vista anatómico, las diferentes entidades clínicas se manifiestan por cambios inflamatorios de magnitud variable y morfología distintiva cen- trados en la vía aérea pequeña, constituida por los bronquiolos menores de $2 \mathrm{~mm}$ de diámetro que no contienen tejido cartilaginoso de sostén en su pared $^{3-5}$.

La bronquiolitis puede presentarse en diversos escenarios clínicos, como enfermedad primaria (bronquiolitis obliterante, por exposición a polvos minerales o gases irritantes, infección viral, etc), como parte de una enfermedad intersticial (neumonitis por hipersensibilidad, bronquiolitis 
respiratoria del fumador o RB-ILD, enfermedad colágeno-vascular) o en el contexto de una enfermedad de la vía aérea de mayor calibre, como sucede en pacientes portadores de asma bronquial, fibrosis quística, enfermedad pulmonar obstructiva crónica o bronquiectasias $s^{1,3-7}$.

El término "bronquiolitis" ha sido empleado por los médicos patólogos con fines descriptivos y por los médicos clínicos con fines diagnósticos, constituyendo un grupo heterogéneo de enfermedades que afectan la vía aérea pequeña de etiología, histopatología, presentación clínica y pronóstico variables $^{1-3}$. Ocasionalmente pueden comprometer la vía aérea proximal o bronquios mayores y/o el espacio aéreo distal ${ }^{2}$. Es una entidad relativamente común asociada a una variedad de condiciones clínicas, incluyendo infecciones, enfermedades del tejido conectivo, reacción a drogas, injuria inhalatoria y trasplante de órganos (médula ósea, pulmón y corazón-pulmón), entre otras ${ }^{1-3}$.

Las dificultades en la definición de esta entidad derivan parcialmente de la diversidad y complejidad de los hallazgos histopatológicos asociados, lo cual nos obliga a considerar los siguientes aspectos $\left.^{1-5}: 1\right)$ Los síndromes clínicos de bronquiolitis se manifiestan por lesiones histopatológicas inespecíficas que se superponen; 2) La presencia de bronquiolitis en una biopsia de tejido pulmonar podría representar una condición primaria (ej: bronquiolitis obliterante o postinfecciosa) o secundaria asociada a otro proceso patológico (ej: EPOC, bronquiectasias).

\section{Consideraciones anatómicas}

La vía aérea pequeña, menor de 2 milímetros de diámetro interno y sin cartílago en el espesor de su pared, comprende a los bronquiolos terminales que cumplen sólo función de conducción y los bronquiolos respiratorios que cumplen función de conducción e intercambio gaseoso ${ }^{3-5}$.

La unidad anatómica básica del pulmón corresponde al lobulillo secundario de Miller, estructura de 10 a 25 milímetros de diámetro rodeada de septos de tejido conectivo, que comprende hasta 20 a 24 acinos. En el centro del lobulillo se encuentra el bronquiolo y la arteria lobulillar, en tanto en su periferia y espacios interlobulillares se encuentran la vena y vasos linfáticos ${ }^{3-6}$. La estructura de mayor tamaño es la arteria, de un milímetro de diámetro, apenas visible en la tomografía computada de tórax. El grosor de la pared del bronquiolo no es mayor a $150 \mu \mathrm{m}$, por lo que únicamente se hace evidente en procesos patológicos, como inflamación y aumento del grosor de la pared o impactación intraluminal de secreciones, exudado o mucus ${ }^{3-7}$. Las lesiones primarias de la vía aérea pequeña son de distribución centrolobulillar, lo cual permite diferenciarlas en los cortes histológicos de otras formas de enfermedad pulmonar difusa.

Los bronquiolos están tapizados por un epitelio cilíndrico ciliado y células secretoras no ciliadas (células Clara), el intersticio peribronquiolar es escaso pero contiene una capa de músculo liso y no tiene glándulas submucosas ${ }^{1,3,7}$. Los bronquiolos terminales están cubiertos por epitelio columnar continuo y dan origen a los bronquiolos respiratorios que contienen alvéolos en su pared.

\section{Clasificación}

Desde un punto de vista operacional, los cuadros de bronquiolitis pueden ser clasificados de acuerdo a los hallazgos clínicos y morfológicos ${ }^{3-7}$ :

\section{a) Cuadro clínico}

Las manifestaciones clínicas varían de acuerdo a la causa de la inflamación bronquiolar, pudiendo corresponder a bronquiolitis infecciosa o post-infecciosa; por inhalación de gases tóxicos, irritantes, polvos minerales u orgánicos; inducida por fármacos; asociada a enfermedad colágeno-vascular o enfermedad inflamatoria intestinal; asociada a trasplante de órganos; aspiración crónica; o causas menos frecuentes como la panbronquiolitis difusa, síndrome ataxia-telangectasia, pénfigo paraneoplásico, entre otras ${ }^{1,3,6,8}$.

Los principales síndromes clínicos de bronquiolitis se describen en la Tabla 1. En esta clasificación se incluyen las condiciones primarias de bronquiolitis y se excluyen otras entidades patológicas definidas que presentan inflamación bronquiolar de magnitud variable. Desde el punto de vista funcional, el compromiso bronquiolar se manifiesta por obstrucción bronquial que puede o no revertir con el uso de broncodilatadores, ocasionalmente defectos restrictivos también pueden ocurrir en afecciones que afectan la vía aérea pequeña ${ }^{1,2,7}$. Más aún, las categorías diagnósticas no son mutuamente excluyentes y se pueden superpo- 
Tabla 1. Clasificación clínica y patológica de los cuadros de bronquiolitis

\begin{tabular}{|c|c|c|}
\hline Variedades de bronquiolitis & Causa o condición asociada & Histopatología \\
\hline Inflamatoria-Infecciosa & $\begin{array}{l}\text { Infección aguda y crónica (virus, Mycoplas- } \\
\text { ma spp, Mycobacterium spp) }\end{array}$ & $\begin{array}{l}\text { Infiltración de la pared bronquiolar con } \\
\text { células inflamatorias }\end{array}$ \\
\hline Bronquiolitis folicular y linfocitaria & $\begin{array}{l}\text { Síndrome de Sjögren, artritis reumatoidea, } \\
\text { inmunodeficiencia }\end{array}$ & $\begin{array}{l}\text { Acumulación de linfocitos en y alrededor } \\
\text { de los bronquiolos }\end{array}$ \\
\hline Bronquiolitis respiratoria & Humo de tabaco & $\begin{array}{l}\text { Acumulación de macrófagos pigmentados } \\
\text { en y alrededor de bronquiolos respira- } \\
\text { torios }\end{array}$ \\
\hline Bronquiolitis constrictiva & $\begin{array}{l}\text { Enfermedad del colágeno, post-infecciosa, } \\
\text { post-trasplante, inhalación de gases } \\
\text { tóxicos }\end{array}$ & $\begin{array}{l}\text { Obliteración progresiva del lumen bron- } \\
\text { quiolar por fibrosis progresiva }\end{array}$ \\
\hline Panbronquiolitis & Idiopática & $\begin{array}{l}\text { Inflamación transmural de la pared bron- } \\
\text { quiolar }\end{array}$ \\
\hline Bronquiectasias & Fibrosis quística post-infecciosa & Bronquiolitis inflamatoria y/o fibrótica. \\
\hline Neumonitis por hipersensibilidad & Agentes orgánicos e inorgánicos inhalados & $\begin{array}{l}\text { Infiltración linfoplasmocitaria bronquiolar } \\
\text { y peribronquiolar }\end{array}$ \\
\hline
\end{tabular}

ner, tales como casos de bronquiolitis constrictiva que se pueden desarrollar como consecuencia de una bronquiolitis infecciosa aguda.

\section{b) Histopatología}

Está relacionada con el fenómeno inflamatorio que se produce en la pared de la vía aérea. Se distinguen cuatro tipos ${ }^{3-7}$ :

- Bronquiolitis celular: Caracterizada por un aumento marcado de las células inflamatorias en la pared bronquiolar, infiltración neutrofílica (cuadro agudo) o linfocitaria (predomina en procesos crónicos), que puede llevar a estrechar el lumen de la vía aérea (Figura 1). Se distingue edema o necrosis de la mucosa y/o submucosa bronquiolar, microabscesos neutrofílicos, hiperplasia de centros germinales (bronquiolitis folicular), y se encuentra asociada a fenómenos inflamatorios ocasionados por agentes infecciosos, inhalación de gases tóxicos, fibrosis quística, bronquiectasias, aspiración crónica, enfermedades del colágeno e inmunodeficiencias crónicas (infección por VIH) ${ }^{1,7,9,10}$.

- Bronquiolitis obliterante con formación de pólipos inflamatorios o endoluminal: Caracterizada por la presencia de tapones de tejido de granulación intraluminal de aspecto polipoideo, con una rica matriz mixoide y de mucopolisacáridos, que estrecha en grado variable el lumen de los bronquiolos hasta eventualmente obliterarlos (Figura 2). Cuando el proceso se centra en los espacios alveolares se denomina neumonía en organización ${ }^{1,3-6}$.

- Bronquiolitis constrictiva: Existen fenómenos de inflamación y fibrosis de magnitud variable en la pared y alrededor de los bronquiolos membranosos y respiratorios que ocasionan estrechamiento u obliteración del lumen por fenómenos cicatriciales, con estasia mucosa e inflamación crónica parcelar que se asocia a bronquiolectasia e hipertrofia del músculo liso bronquiolar $^{11-15}$ (Figura 3).

- Fibrosis peribronquial y metaplasia bronquiolar ("Lambertosis"): La fibrosis se extiende por las paredes alveolares y ocasionalmente bronquiolos respiratorios que terminan en múltiples canales fibrosos cubiertos por epitelio cuboideo. Puede ser idiopática o asociada a daño bronquiolar en fase de recuperación, neumonitis por hipersensibilidad crónica, inflamación de la vía aérea distal a bronquiectasias y enfermedades pulmonares difusas ${ }^{1,3-8}$.

\section{Cuadro clínico}

La presentación clínica de la enfermedad es muy variable $y$, ocasionalmente anodina, dependiendo de la causa, tiempo de evolución y gravedad de la misma ${ }^{1,2,7}$. Clásicamente de curso crónico (ej: aspiración crónica, bronquiolitis post trasplante, fibrosis quística) y menos frecuentemente de 


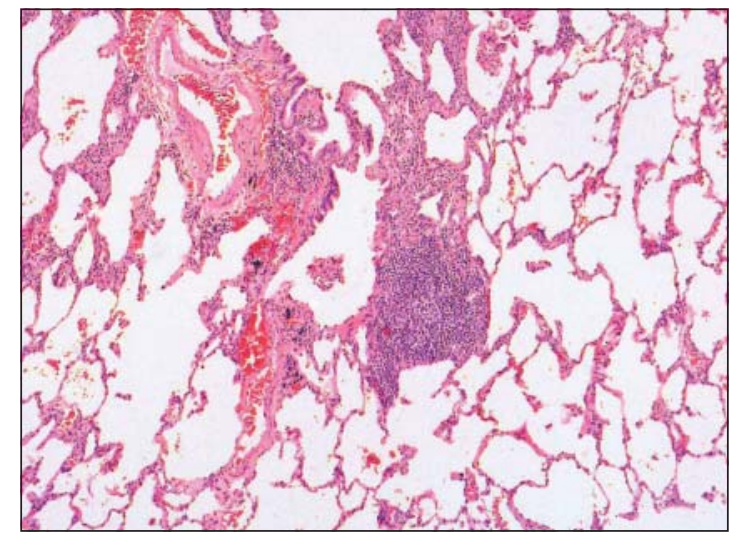

Figura 1. Bronquiolitis linfocitaria. Tinción de hematoxilina $y$ eosina de $10 X$

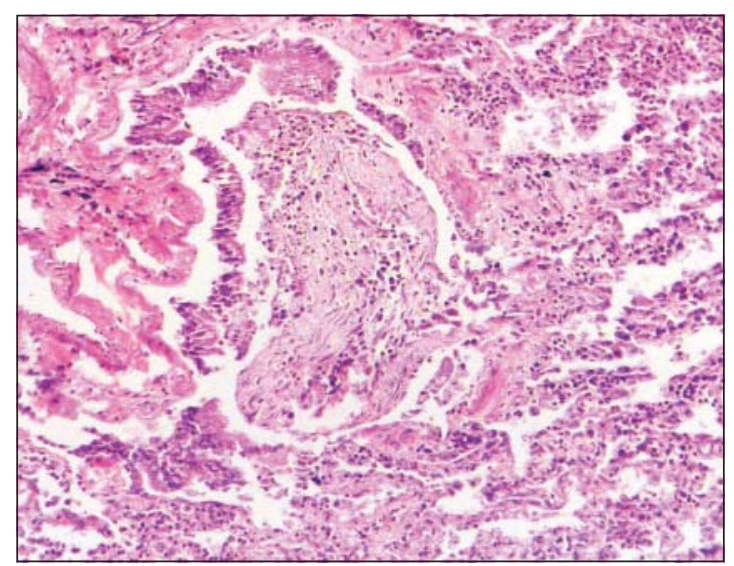

Figura 2. Bronquiolitis obliterante. Tinción de hematoxilina $y$ eosina de $10 X$.

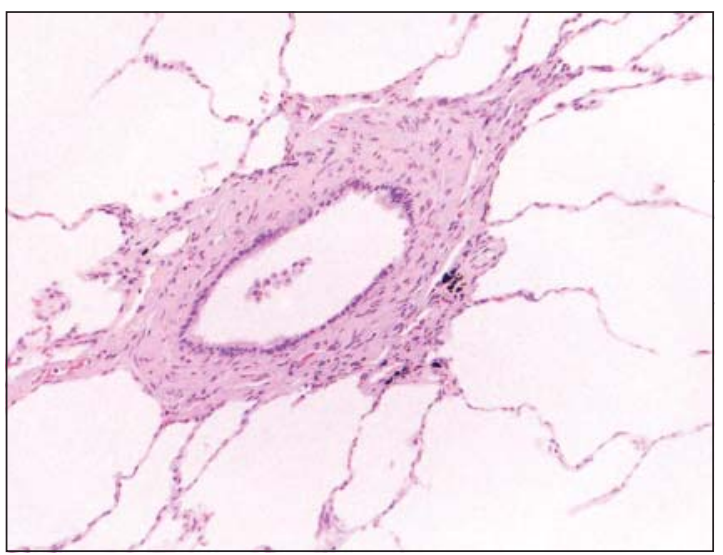

Figura 3. Bronquiolitis constrictiva idiopática. Tinción de hematoxilina y eosina de $10 \mathrm{X}$. evolución aguda (ej: infección viral, inhalación de gases tóxicos) o subaguda (ej: infección por micobacterias no tuberculosas). Habitualmente se manifiesta por disnea de esfuerzos progresiva de magnitud variable y tos irritativa o productiva, con síntomas y signos de obstrucción bronquial, con o sin manifestaciones sistémicas ${ }^{1-7}$.

En la evaluación funcional respiratoria predomina el patrón de obstrucción bronquial de magnitud variable que no revierte con el uso de broncodilatadores, aunque en las etapas iniciales la función pulmonar puede estar conservada, y en los cuadros avanzados con extensa fibrosis bronquiolar puede haber un patrón restrictivo ${ }^{1,6,7}$.

La capacidad de difusión pulmonar $\left(\mathrm{DL}_{\mathrm{CO}}\right)$ usualmente es normal, salvo en condiciones asociadas a daño bronquiolar extenso, como ocurre en la neumonitis por hipersensibilidad y neumonías en organización primarias o secundarias. En pacientes con extenso compromiso de estructuras alveolares (ej: bronquiolitis obliterante con neumonía en organización) puede haber hipoxemia y aumento de la diferencia alvéolo-arterial de oxígeno que se incrementan durante el ejercicio ${ }^{1,6,7}$.

Pese a no existir marcadores de laboratorio específicos, deben considerarse las exploraciones y exámenes de laboratorio que permitan descartar causas infecciosas, inmunológicas y sistémicas, especialmente cuando el cuadro clínico inespecífico no permite aclarar la causa ${ }^{3-6}$.

\section{Radiología}

La vía aérea pequeña no es visible en condiciones normales en la radiología convencional ni en la tomografía axial computada de tórax ${ }^{6,16}$. Sin embargo, la enfermedad bronquiolar se asocia a fenómenos inflamatorios y/o fibróticos que aumentan el grosor de la pared bronquiolar y ocasionan dilatación de los bronquiolos, impactación intraluminal por mucus o secreciones o cambios indirectos de la perfusión en regiones del parénquima pulmonar mal ventiladas y con atrapamiento aéreo ${ }^{16,17}$. Los cambios anatómicos descritos determinan los hallazgos radiográficos típicos de esta entidad clínica ${ }^{16-18}:$ a) Signos directos: Nódulos centrolobulillares y compromiso bronquiolar con patrón tipo "árbol en brote" (Figuras 4-6), yb) Signos indirectos: Patrón de perfusión en mosaico, mejor visualizados en la tomografía computada de 


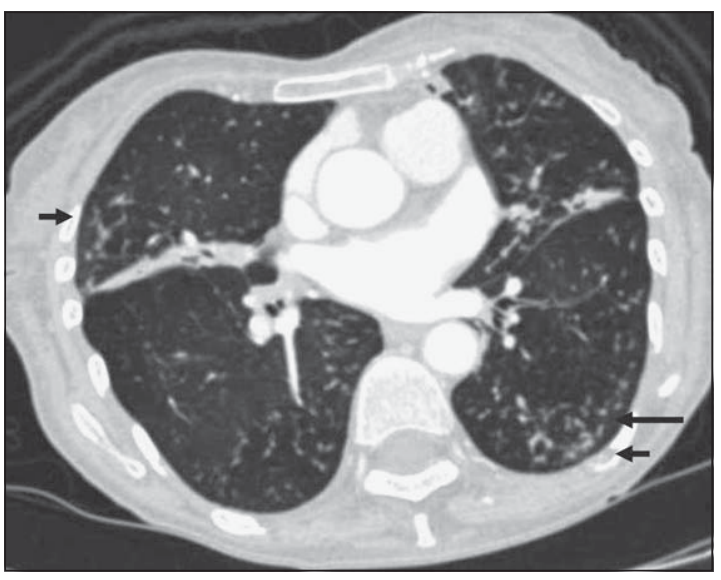

Figura 4. Mujer de 75 años con trastorno de la deglución severo y síndrome de aspiración crónica. La imagen tomográfica muestra múltiples opacidades centrolobulillares con patrón de árbol en brote (flechas).

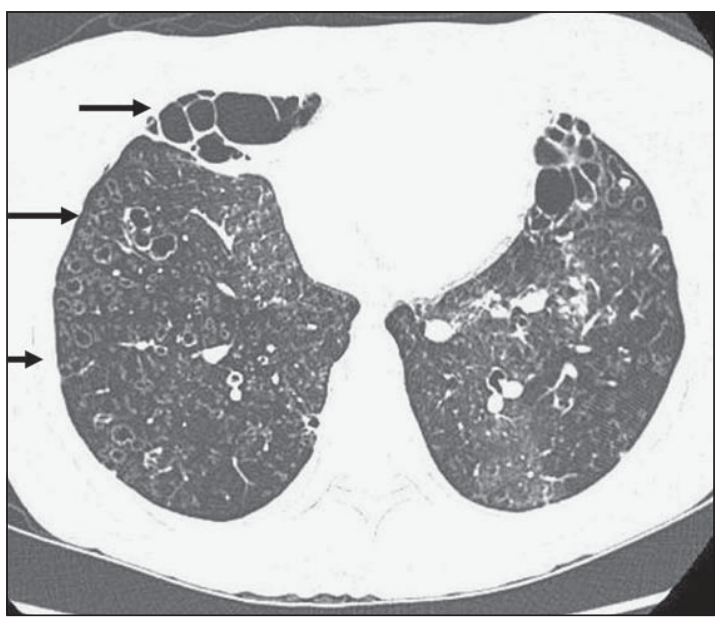

Figura 6. Mujer de 46 años portadora de fibrosis quística. La imagen tomográfica muestra extensas bronquiectasias quísticas y varicoides asociado a bronquioloectasias cilíndricas difusas (flechas) con algunas opacidades centrolobulillares con patrón de árbol en brote.

alta resolución (HRCT) y, especialmente el fenómeno de atrapamiento aéreo, pesquisado con las imágenes en espiración (Figura 7). Estos hallazgos no sólo aumentan la sensibilidad del examen sino que permiten obviar la necesidad de administrar medio de contraste, lo cual no es requerido salvo en condiciones excepcionales.

En el diagnóstico diferencial clínico-radiográfico de esta entidad (Tabla 2) debemos considerar lo siguiente $e^{6,16-18}$ :

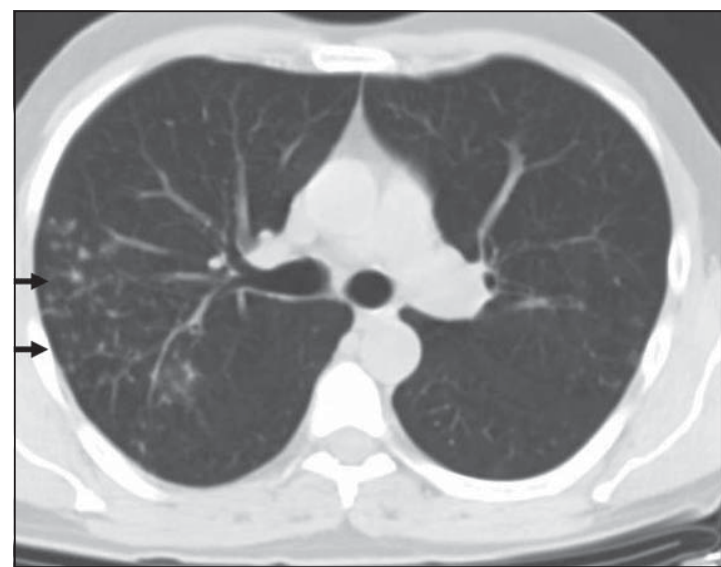

Figura 5. Hombre de 56 años con infección por Mycobacterium avium-intracellulare y patrón de bronquiolitis celular. La imagen tomográfica muestra opacidades centrolobulillares con patrón de árbol en brote y bronquioloectasias (flechas).

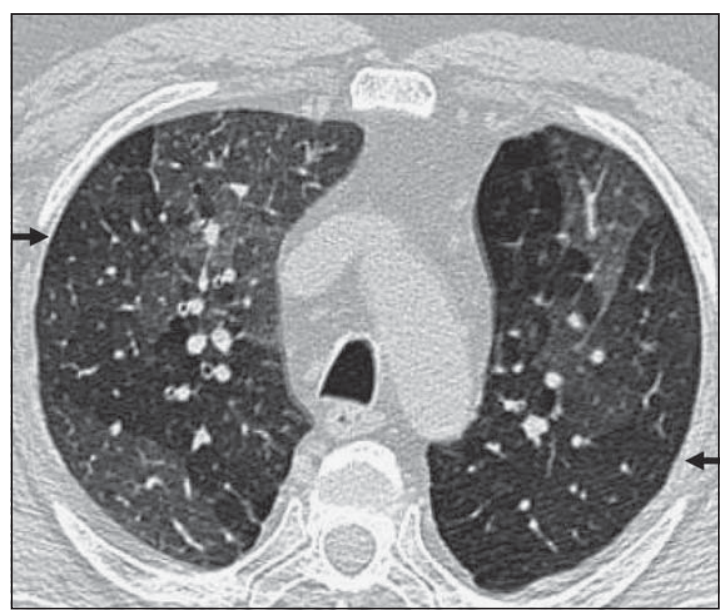

Figura 7. Hombre de 56 años portador bronquiolitis constrictiva idiopática. La imagen tomográfica muestra áreas de atrapamiento aéreo de distribución en mosaico (flechas).

a) Nódulos centrilobulillares: Opacidades mal definidas en vidrio esmerilado situadas en el centro del lobulillo, focales o difusas, alejadas al menos $5 \mathrm{a} 10 \mathrm{~mm}$ de la superficie pleural. Se observan en enfermedades infecciosas del parénquima pulmonar, neumonitis por hipersensibilidad, enfermedades colágeno-vascular, carcinoma bronquioloalveolar, toxicidad por agentes inhalados, bronquiolitis respiratoria del fumador (RB-ILD), entre otras. 
Bronquiolitis del adulto - F. Saldías et al

Tabla 2. Características radiológicas de los cuadros de bronquiolitis en la tomografía axial computada de tórax

\begin{tabular}{|c|c|c|}
\hline Tipo de bronquiolitis & Características radiológicas & Diagnóstico diferencial \\
\hline Inflamatoria-infecciosa & $\begin{array}{l}\text { Nódulos centrilobulillar } \\
\text { Patrón de árbol en brote }\end{array}$ & Neumonitis por hipersensibilidad \\
\hline Bronquiolitis folicular y linfocitaria & $\begin{array}{l}\text { Patrón de árbol en brote } \\
\text { Nódulos, quistes }\end{array}$ & $\begin{array}{l}\text { Bronquiolitis celular } \\
\text { Panbronquiolitis }\end{array}$ \\
\hline Bronquiolitis respiratoria & $\begin{array}{l}\text { Nódulos centrilobulillar } \\
\text { Opacidad en vidrio esmerilado }\end{array}$ & Neumonitis por hipersensibilidad \\
\hline Bronquiolitis constrictiva & $\begin{array}{l}\text { Atenuación en mosaico } \\
\text { Bronquiectasias } \\
\text { Atrapamiento de aire en la espiración }\end{array}$ & $\begin{array}{l}\text { Asma bronquial } \\
\text { Enfisema panacinar } \\
\text { Hiperplasia neuroendocrina }\end{array}$ \\
\hline Panbronquiolitis & $\begin{array}{l}\text { Patrón de árbol en brote } \\
\text { Bronquiolectasias } \\
\text { Bronquiectasias }\end{array}$ & $\begin{array}{l}\text { Bronquiolitis celular } \\
\text { Bronquiolitis folicular } \\
\text { Otras causas de bronquiectasias }\end{array}$ \\
\hline Bronquiectasias & $\begin{array}{l}\text { Patrón de árbol en brote } \\
\text { Atrapamiento de aire } \\
\text { Bronquiolectasias }\end{array}$ & Otras causas de bronquiolitis \\
\hline Neumonitis por hipersensibilidad & $\begin{array}{l}\text { Nódulos centrilobulillar } \\
\text { Atenuación en mosaico } \\
\text { Opacidad en vidrio esmerilado }\end{array}$ & Bronquiolitis respiratoria \\
\hline
\end{tabular}

b) Árbol en brote: Grupos de nódulos bien definidos adyacentes a ramificaciones centrilobulillares o estructuras tubulares, resultantes de extensa impactación mucosa en la vía aérea pequeña. Las líneas y nódulos corresponden a la vía aérea expandida visualizada en el plano perpendicular o plano de sección de la tomografía. Causas: infección (en particular por Mycobacterium spp), enfermedad colágenovascular, aspiración crónica, neoplasias, aspergilosis broncopulmonar alérgica, etc.

c) Atenuación en mosaico: Heterogeneidad radiológica, existen zonas con aumento relativo de la densidad que alternan con áreas en las que está disminuida, confiriendo al parénquima un aspecto geográfico. Se observa en condiciones caracterizadas por obstrucción bronquial difusa (ej: inhalación de gases tóxicos), tromboembolismo pulmonar (agudo y crónico), bronquiolitis obliterante post-trasplante, neumonitis por hipersensibilidad, etc.

El patrón clínico-radiográfico permite establecer el diagnóstico en una elevada proporción de los casos sin requerir exámenes invasivos, tales como biopsia transbronquial o pulmonar por videotoracoscopia (VATS). En la Tabla 3 se describe el proceso diagnóstico que se recomienda utilizar en pacientes con sospecha de enfermedad bronquiolar.

\section{Variedades de bronquiolitis primaria}

Las principales categorías diagnósticas son ${ }^{1-8}$ :

\section{a) Bronquiolitis infecciosa}

Ocasionada especialmente por agentes virales (virus sincicial respiratorio, adenovirus, influenza, parainfluenza), Mycoplasma pneumoniae, Mycobacterium spp y otras ${ }^{1,7}$. En la histología predomina el patrón celular con inflamación de la pared bronquiolar aunque en la bronquiolitis postinfecciosa puede predominar el patrón constrictivo ${ }^{1,7,9-11}$. En la evaluación funcional respiratoria destaca el patrón obstructivo que no revierte con broncodilatadores.

La bronquiolitis aguda de la infancia se manifiesta por signos de obstrucción bronquial asociada a fiebre de bajo grado y tos irritativa que pueden persistir durante varias semanas ${ }^{9-11}$. Los cuadros graves, especialmente en adultos, pueden 
Tabla 3. Evaluación clínico-radiográfica de los pacientes con sospecha de enfermedad bronquiolar

1. Historia y examen físico

Infección

Exposición a gases tóxicos

Reacción a drogas

Manifestaciones sistémicas

Trasplante de órganos

2. Radiografía de tórax y evaluación funcional respiratoria

Signos de hiperinsuflación pulmonar

Patrón de obstrucción bronquial

3. Tomografía computada de tórax (HRCT)

a) Patrón de árbol en brote

Focal: Bronquiolitis infecciosa (virus, bacterias, micobacterias, hongos, parásitos), menos común: aspergilosis broncopulmonar alérgica, papilomatosis laringo-traqueo-bronquial juvenil, asociada a enfermedad del colágeno.

Difuso: Síndrome de aspiración crónica, panbronquiolitis difusa. Enfermedades congénitas: fibrosis quística, síndrome de cilio inmóvil.

\section{b) Nódulos centrilobulillar}

Fumadores: Bronquiolitis respiratoria, RB-ILD. Menos común: histiocitosis pulmonar de células de Langerhans, insuficiencia cardiaca congestiva, linfoma, carcinoma bronquioloalveolar.

No fumadores: Neumonitis por hipersensibilidad subaguda.

c) Patrón en mosaico-Atrapamiento aéreo

Bronquiolitis constrictiva

Bronquiolitis obliterante

\section{Procedimientos invasivos}

Biopsia pulmonar quirúrgica (procedimiento de elección)

Lavado broncoalveolar y biopsia transbronquial (en casos seleccionados)

acompañarse de anomalías radiográficas extensas incluyendo un patrón de relleno alveolar difuso. El virus sincicial respiratorio es el principal agente causal en la edad pediátrica pero otros virus (adenovirus, influenza, parainfluenza) y patógenos respiratorios (Mycoplasma spp, Bordetella pertussis) pueden ocasionar un cuadro similar. Debido a las limitaciones de sensibilidad y especificidad de los exámenes microbiológicos, en muchos casos, especialmente en adultos, el agente causal no logra ser identificado.

Debido a su curso benigno y autolimitado, la bronquiolitis aguda viral rara vez se encuentra en material de biopsia. Los principales hallazgos histopatológicos de la bronquiolitis infecciosa son la infiltración celular mononuclear y neutrofílica intensa en la pared bronquiolar ${ }^{3,5,9}$. En los casos graves puede haber necrosis del epitelio bronquiolar, y por definición, no se observa proliferación de fibroblastos ni depósito de colágeno. Ocasionalmente, el cuadro puede evolucionar hacia la obliteración fibrosa de la vía aérea pequeña, ocasionando limitación crónica del flujo aéreo ${ }^{1,7,9}$. De hecho, en algunos pacientes puede evolucionar con los hallazgos morfológicos característicos de la bronquiolitis constrictiva.

\section{b) Bronquiolitis respiratoria}

La bronquiolitis respiratoria (RB) se reconoce por la presencia intraluminal de macrófagos cargados de pigmento en el extremo distal de los bronquiolos con extensión a la región alveolar ${ }^{1,3}$. El pigmento finamente granular de los macrófagos alveolares representa depósitos de metabolitos y productos de desecho del humo de tabaco. No se visualiza necrosis del epitelio bronquiolar pero puede haber infiltración de la mucosa por histiocitos, macrófagos y algunos linfocitos. La bronquiolitis respiratoria asociada a enfermedad pulmonar intersticial (RB-ILD) mantiene las características morfológicas descritas asociado a neumonía intersticial descamativa (DIP) ${ }^{5}$. Esta condición se presenta en adultos jóvenes grandes fumadores y responde favorablemente a la suspensión del 
hábito tabáquico. El tratamiento con esteroides sistémicos permite reducir la inflamación local y acelera la recuperación funcional.

\section{c) Bronquiolitis folicular}

La bronquiolitis folicular se reconoce por la hiperplasia del tejido linfoide a lo largo de la vía aérea, incluyendo los bronquios mayores, y por el desarrollo de folículos y centros germinales ${ }^{1,3,5,19}$. Los linfocitos son policlonales en el análisis inmunohistoquímico. Los folículos ocasionalmente ocluyen el lumen bronquiolar ocasionando infección secundaria y focos de neumonía adyacentes a la vía aérea pequeña. La bronquiolitis folicular puede estar presente en otras variedades de bronquiolitis sin alterar la clasificación diagnóstica. Esta entidad se observa en infecciones virales recurrentes, síndromes de inmunodeficiencias y enfermedades colágeno-vascular ${ }^{20}$. La bronquiolitis folicular junto con la neumonía intersticial linfocítica y los granulomas de células epitelioideas forman parte del espectro de reacción morfológica de la alveolitis alérgica extrínseca. En el diagnóstico diferencial debemos considerar el linfoma variedad BALT, el cual se reconoce por la presencia de lesiones linfoepiteliales y linfocitos monoclonales.

En la infancia, el pronóstico está relacionado con el agente causal ${ }^{21}$. La entidad asociada a infecciones virales recurrentes tiene buen pronóstico, mejora con las medidas preventivas, cuando el niño crece y el sistema inmune madura. En los casos asociados a inmunodeficiencia primaria o adquirida el pronóstico es peor, y en la bronquiolitis folicular idiopática ningún tratamiento logra detener el proceso y la mayoría de los niños fallecen dentro de algunos años de iniciada la enfermedad.

\section{d) Bronquiolitis obliterante}

El término "bronquiolitis constrictiva u obliterante" fue empleado inicialmente para describir lesiones bronquiolares caracterizadas por fibrosis peribronquial y de la submucosa, sin proliferación de fibroblastos, asociados a células mononucleares y neutrófilos, especialmente en las fases iniciales del proceso ${ }^{1,7,11-15}$. Además, los bronquiolos pueden exhibir ectasia o impactación de mucus. La distribución de las lesiones es heterogénea y focal, lo cual dificulta el proceso diagnóstico especialmente cuando es realizado por un profesional inexperto o se examinan muestras pequeñas. En los casos avanzados, el diagnóstico puede verse dificultado por la ausencia de inflamación activa y desaparición de los bronquiolos, las tinciones de elastina podrían ser de utilidad para identificar las estructuras afectadas. Los cambios morfológicos de la bronquiolitis constrictiva son considerados irreversibles.

Los pacientes con bronquiolitis constrictiva refieren disnea de esfuerzos progresiva y limitación de la capacidad de ejercicio asociados a limitación crónica del flujo aéreo, determinada por el estrechamiento concéntrico y eventual obliteración del lumen bronquiolar ${ }^{1-15}$. La radiografía de tórax puede ser normal o presentar signos de hiperinsuflación pulmonar. En la tomografía es característico el patrón de atenuación en mosaico ${ }^{16-18}$. El curso clínico de la enfermedad es progresivo y a menudo conduce a la insuficiencia respiratoria crónica.

Tabla 4. Síndromes clínicos asociados a cuadros de bronquiolitis constrictiva

Receptor de aloinjerto
Trasplante de médula ósea
Trasplante de pulmón y corazón-pulmón
Enfermedad injerto versus huésped
Enfermedad colagenovascular
Artritis reumatoidea
Fasceitis eosinofílica
Lupus eritematoso sistémico
Post infecciosa
Viral (sincicial respiratorio, adenovirus, influenza, para-
influenza)
Mycoplasma spp
Toxinas inhaladas o ingeridas
Dióxido de nitrógeno
Dióxido de sulfuro
Amonio
Cloro
Fosgeno
Diacetil (trabajadores de popcorn)
Sauropus androgynus
Drogas
Penicilamina
Sales de oro
Lomustina (CCNU)
Cocaína
Misceláneos
Colitis ulcerosa
Hiperplasia de células endocrinas/tumorlets carcinoide
múltiples
Idiopática


En la Tabla 4 se describen las principales causas de bronquiolitis obliterante, destacando los casos asociados a enfermedades colágeno-vasculares (ej: artritis reumatoidea de larga evolución), exposición a gases irritantes, trasplantes de médula ósea y pulmón, drogas y colitis ulcerosa.

A continuación, se describen las principales causas de bronquiolitis obliterante:

d1) Bronquiolitis obliterante por inhalación de gases irritantes: Se produce inflamación severa y ulceración de la mucosa que ocasiona bronquiolitis constrictiva ${ }^{15,22-24}$. El cuadro clínico suele ser de inicio agudo, de magnitud variable, con síntomas que afectan la vía aérea superior hasta cuadros de daño alveolar difuso o sindrome de distrés respiratorio agudo. Luego de un período de latencia puede seguir un curso crónico, irreversible, caracterizado por tos, disnea y signos de obstrucción bronquial $^{22-24}$. La distribución y extensión del daño bronquiolar dependen de la concentración del agente, duración de la exposición, solubilidad y reactividad biológica del agente y susceptibilidad individual. Los principales agentes causales son el amonio, óxido de nitrógeno, humo de incendios, dióxido de azufre, cloro y cocaína.

d2) Bronquiolitis asociada a algunas enfermedades del colágeno, tales como la artritis reumatoidea, lupus eritematoso sistémico, síndrome de Sjögren, espondilitis anquilosante, esclerodermia y enfermedad de Behçet ${ }^{1-7}$.Se manifiesta por tos y disnea progresiva, con signos de obstrucción bronquial, y $\mathrm{DL}_{\mathrm{CO}}$ dentro de rangos normales. De hecho, se pesquisan bronquiectasias hasta en 30\% de los pacientes con artritis reumatoidea de larga evolución. En su manejo se han propuesto varias alternativas terapéuticas: prednisona, ciclofosfamida, etanercept y macrólidos, sin lograr definir aún la mejor opción de tratamiento ${ }^{25,26}$.

d3) Drogas: Sales de oro, penicilamina, tiopronina, Sauropus androgynus. El daño anatómico puede variar en severidad desde la inflamación bronquiolar hasta la bronquiolitis constrictiva severa ${ }^{1,6,7}$.

d4) Bronquiolitis obliterante asociada a la inhalación de polvos minerales: Inflamación bronquiolar ocasionada por el depósito de partículas de polvo inorgánico en la vía aérea pequeña, estimulando la proliferación de fibroblastos y producción de colágeno que pueden llevar a bronquiolitis constrictiva. Morfológicamente indistinguible del daño bronquiolar inducido por tabaco, puede ser ocasionada por cristales de asbesto, óxido de hierro, talco, silicatos y carbón ${ }^{3-6}$.

d5) Bronquiolitis obliterante asociada a trasplantes: Esta entidad se reconoce en la enfermedad injerto contra hospedero crónica (cGVHD), complicación tardía y grave del trasplante pulmonar y de células hematopoyéticas ${ }^{27-30}$. El compromiso pulmonar de la cGVHD se manifiesta como un cuadro de bronquiolitis obliterante, presentándose en 2 a 3\% de los receptores de trasplante de médula ósea autólogos $27-29,31$. Esta complicación se ha atribuido a la aloinmunización contra antígenos del epitelio bronquiolar por linfocitos $\mathrm{T}$ del donante ${ }^{31-33}$, con compromiso de la vía aérea pequeña que ocasiona fenómenos de bronquiolitis obliterante. Se manifiesta por la aparición de disnea, tos seca y signos de obstrucción bronquial que no revierten con el uso de broncodilatadores, habitualmente después de los cuatro meses del trasplante ${ }^{27-29}$. El deterioro progresivo del $\mathrm{VEF}_{1}$ en la espirometría constituye un elemento diagnóstico y también pronóstico, ya que a mayor caída del $\mathrm{VEF}_{1}$ peor es el pronóstico ${ }^{28,31,32}$. El compromiso pulmonar se acompaña de compromiso de otros órganos: piel, ojos, hígado, intestino, etc. Los principales factores de riesgo de compromiso pulmonar lo constituyen la presencia de GVHD en otros órganos, niveles séricos bajos de inmunoglobulina $\mathrm{G}$, inducción con busulfán, metotrexato o radioterapia e infección pulmonar en los primeros 100 días de trasplante ${ }^{28,31}$. El pronóstico de esta condición se ha mantenido invariable en las últimas décadas, con una sobrevida media de $44 \%$ a 2 años y $13 \%$ a 5 años ${ }^{28,32}$. Menos de $20 \%$ de los pacientes mejora con el tratamiento inmunosupresor y a los tres años habrán fallecido dos tercios de ellos, siendo nuestra mejor opción lograr estabilizar esta condición y prevenir el deterioro funcional respiratorio (caída progresiva del $\left.\mathrm{VEF}_{1}\right)^{28,31}$.

Una vez excluidas las causas infecciosas, manejado el reflujo gastroesofágico e iniciado la profilaxis contra la infección por Pneumocystis jiroveci, 
el tratamiento de la GVHD pulmonar considera el uso de corticoides sistémicos en dosis altas e inmunosupresores como ciclosporina, tacrolimus o azatioprina. Además, se han empleado nuevos esquemas con globulina antitimocito, sirolimus, anti-TNF, imatinib, azitromicina y corticoides inhalados, todos ellos anecdóticos y con resultados dispares ${ }^{28,29,31,32}$. En casos avanzados se ha intentado el trasplante pulmonar, sobre el cual puede recurrir el síndrome de bronquiolitis obliterante ${ }^{31,33}$.

\section{e) Bronquiolitis por aspiración difusa}

Ocasionada por la aspiración crónica de material extraño que lleva a inflamación crónica de la pared bronquiolar con reacción de cuerpo extraño. Se observa en sujetos ancianos, pacientes postrados y portadores de trastornos neurológicos crónicos (ej: enfermedad cerebrovascular, miopatías, polineuropatías) $)^{8,34}$.

\section{f) Panbronquiolitis difusa}

Esta entidad clínica afecta casi exclusivamente a hombres japoneses en la cuarta y quinta década de la vida ${ }^{35-38}$. Los hallazgos histopatológicos de esta condición (Figura 8) se superponen con otras entidades clínicas, tales como bronquiectasias idiopáticas, bronquiolitis constrictiva, bronquiolitis constrictiva asociada a artritis reumatoidea, colitis ulcerosa, granulomatosis y angeítis alérgica, leucemia de células $\mathrm{T}$ del adulto y linfoma no Hodgkin. La enfermedad se manifiesta insidiosamente con síntomas y signos de obstrucción bronquial difusa $\mathrm{a}^{36-38}$. La mayoría de los pacientes tienen bronquiectasias asociadas a sinusitis crónica

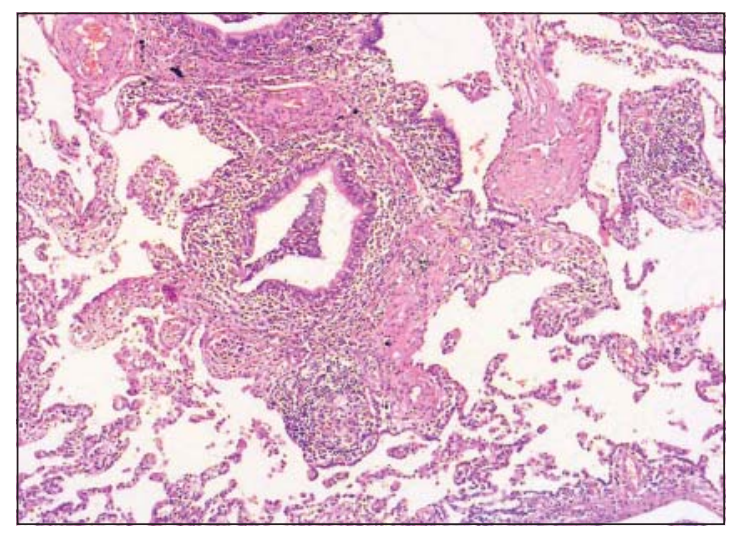

Figura 8. Panbronquiolitis difusa. Tinción de hematoxilina $y$ eosina de $10 \mathrm{X}$
(75\% de los casos), lo cual sugiere la presencia de alguna anomalía de la función ciliar.

Los pacientes con panbronquiolitis difusa desarrollan múltiples episodios de infección bacteriana, y a menudo están colonizados con Pseudomonas aeruginosa ${ }^{38}$. El 30\% de los pacientes fallecen en los primeros diez años de evolución de la enfermedad, usualmente por progresión inexorable de la obstrucción bronquiolar difusa y anomalías del intercambio gaseoso ${ }^{37}$. El tratamiento con dosis bajas de eritromicina ha demostrado su eficacia en algunos casos ${ }^{39}$.

Los hallazgos histopatológicos característicos de esta entidad son la inflamación bronquiolocéntrica, la hiperplasia linfoide y acumulación de células espumosas (foam cells) en el intersticio pulmonar ${ }^{37,38}$. Hallazgos similares se observan en pacientes con bronquiectasias y fibrosis quística, pero la tríada clásica ha sido observada en menos del 10\% de los pacientes con bronquitis crónica, neumonitis por hipersensibilidad, bronquiolitis folicular y bronquiolitis constrictiva idiopática ${ }^{40}$.

\section{Referencias}

1. Ryu JH, Myers JL, Swensen SJ. Bronchiolar disorders. Am J Respir Crit Care Med 2003; 168: 1277-92.

2. King TE Jr. Overview of bronchiolitis. Clin Chest Med 1993; 14: 607-10.

3. Popper HH. Bronchiolitis, an update. Virchows Arch 2000; 437: 471-81.

4. Colby TV. Bronchiolitis. Pathologic considerations. Am J Clin Pathol 1998; 109: 101-9.

5. Visscher DW, Myers JL. Bronchiolitis. The pathologist`s perspective. Proc Am Thoracic Soc 2006; 3: 41-7.

6. Devakonda A, Raoof S, Sung A, Travis WD, Naidich D. Bronchiolar disorders: A clinical-radiological diagnostic algorithm. Chest 2010; 137: 938-51.

7. Ryu JH. Classification and approach to bronchiolar diseases. Curr Opin Pulm Med 2006; 12: 145-51.

8. Costabel U, du Bois E. Diffuse parenchymal lung disease. Prog Respir Res 2007; 36: 292-306.

9. Aherne W, Bird T, Court SD, Gardner PS, McQuillin J. Pathological changes in virus infections of the lower respiratory tract in children. J Clin Pathol 1970; 23: 7-18.

10. Kindt GC, Weiland JE, Davis WB, Gadek JE, Dorinsky PM. Bronchiolitis in adults. A reversible cause of airway obstruction associated with airway neutrophils and neutrophil products. Am Rev Respir Dis 1989; 140: 483-92.

11. Hardy KA, Schidlow DV, Zaeri N. Obliterative bronchiolitis in children. Chest 1988; 93: 460-6. 
12. Garg K, Lynch DA, Newell JD, King TE Jr. Proliferative and constrictive bronchiolitis: classification and radiologic features. AJR Am J Roentgenol 1994; 162: 803-8.

13. Turton CW, Williams G, Green M. Cryptogenic obliterative bronchiolitis in adults. Thorax 1981; 36: 805-10.

14. Kraft M, Mortenson RL, Colby TV, Newman L, Waldron JA Jr, King TE Jr. Cryptogenic constrictive bronchiolitis. A clinicopathologic study. Am Rev Respir Dis 1993; 148: 1093-101.

15. Markopoulo KD, Cool CD, Elliot TL, Lync DA, Newell JD Jr, Hale VA, et al. Obliterative bronchiolitis: varying presentations and clinicopathological correlation. Eur Respir J 2002; 19: 20-30.

16. Müller NL, Miller RR. Diseases of the bronchioles: CT and histopathologic findings. Radiology 1995; 196: 3-12.

17. Essadki O, Grenier Ph. Les bronchiolites: Signes tomodensitométriques. J Radiol 1999; 80: 17-24.

18. Pipavath SJ, Lynch DA, Cool C, Brown KK, Newell JD. Radiologic and pathologic features of bronchiolitis. AJR Am J Roentgenol 2005; 185: 354-63.

19. Yousem SA, Colby TV, Carrington CB. Follicular bronchitis/bronchiolitis. Hum Pathol 1985; 16: 700-6.

20. Wells AU, du Bois RM. Bronchiolitis in association with connective tissue disorders. Clin Chest Med 1993; 14: 655-66.

21. Kinane BT, Mansell AL, Zwerdling RG, Lapey A, Shannon DC. Follicular bronchitis in the pediatric population. Chest 1993; 104: 1183-6.

22. Douglas WW, Hepper NG, Colby TV. Silo-filler's disease. Mayo Clin Proc 1989; 64: 291-304.

23. Konichezky S, Schattner A, Ezri T, Bokenboim P, Geva D. Thionyl-chloride-induced lung injury and bronchiolitis obliterans. Chest 1993; 104: 971-3.

24. Wang B, Peng Z, Zhang X, Xu Y, Wang H, Allen G, Wang L, Xu X. Particulate matter, sulfur dioxide, and pulmonary function in never-smoking adults in Chongqing, China. Int J Occup Environ Health 1999; 5: 14-9.

25. Wells AU, du-Bois RM. Bronchiolitis in association with connective tissue disorders. Clin Chest Med 1993; 14: 655-66.

26. Cortot AB, Cottin V, Miossec P, Fauchon E, ThivoletBéjui F, Cordier JF. Improvement of refractory rheumatoid arthritis-associated constrictive bronchiolitis with etanercept. Resp Med 2005; 99: 511-4.

27. Bhushan V, Collins RH Jr. Chronic graft-vs-host disease. JAMA 2003; 290: 2599-603.
28. Williams KM, Chien JW, Gladwin MT, Pavletic SZ Bronchiolitis obliterans after allogeneic hematopoietic stem cell transplantation. JAMA 2009; 302: 306-14.

29. Copelan EA. Hematopoietic stem-cell transplantation. N Engl J Med 2006; 354: 1813-26.

30. Belperio JA, Weigt SS, Fishbein MC, Lynch JP III. Chronic lung allograft rejection: mechanisms and therapy. Proc Am Thorac Soc 2009; 6: 108-21.

31. Soubani AO, Uberti JP. Bronchiolitis obliterans following haematopoietic stem cell transplantation. Eur Respir J 2007; 29: 1007-19.

32. Chien JW, Duncan S, Williams KM, Pavletic SZ. Bronchiolitis obliterans syndrome after allogeneic hematopoietic stem cell transplantation-an increasingly recognized manifestation of chronic graft-versus-host disease. Biol Blood Marrow Transplant 2010; 16 (1 Suppl): S106-14.

33. Sano Y, Date H, Nagahiro I, Aoe M, Shimizu N. Livingdonor lobar lung transplantation for bronchiolitis obliterans after bone marrow transplantation. Ann Thorac Surg 2005; 79: 1051-2.

34. Matsuse T, Oka T, Kida K, Fukuchi Y. Importance of diffuse aspiration bronchiolitis caused by chronic occult aspiration in the elderly. Chest 1996; 110: 1289-93.

35. Sugiyama Y, Kudoh S, Maeda H, Suzaki H, Takaku F. Analysis of HLA antigens in patients with diffuse panbronchiolitis. Am Rev Respir Dis 1990; 141: 1459-62.

36. Nishimura K, Kitaichi M, Izumi T, Itoh H. Diffuse panbronchiolitis: correlation of high-resolution CT and pathologic findings. Radiology 1992; 184: 779-85.

37. Iwata M, Sato A, Colby TV. Diffuse panbronchiolitis. In: GR Epler (ed). Diseases of the bronchioles. Raven Press, New York, 1994, pp 153-79.

38. Kamoshida T. Clinicopathological study of diffuse panbronchiolitis-with special reference to relationship between the clinical duration and respiratory bronchiolar lesions. Nihon Kyobu Shikkan Gakkai Zasshi 1993; 31: 169-79.

39. Kudoh S, Azuma A, Yamamoto M, Izumi T, Ando M. Improvement of survival in patients with diffuse panbronchiolitis treated with low-dose erythromycin. Am J Respir Crit Care Med 1998; 157: 1829-32.

40. Iwata M, Colby TV, Kitaichi M. Diffuse panbronchiolitis: diagnosis and distinction from various pulmonary diseases with centrilobular interstitial foam cell accumulations. Hum Pathol 1994; 25: 357-63. 